\title{
HEALTH SEEKING BEHAVIOR OF PSYCHIATRIC PATIENTS AT AN OUTPATIENT DEPARTMENT OFA TERTIARY CARE HOSPITAL IN LAHORE, PAKISTAN
}

\author{
Muhammad Ashraf Chaudhry ${ }^{1}$, Aneeqa Shamshad Butt ${ }^{2}$, Ejaz Ahmad Khan ${ }^{3}$, Asma Abdul Latif ${ }^{4}$, Jalil \\ Kamran $^{5}$, Mumtaz Ali Khan $^{6}$, Muhammad Saleem Rana $^{7}$
}

\author{
${ }^{1}$ Contech International Health Consultants, Lahore, Pakistan, \\ ${ }^{2}$ Allama lqbal Medical College, Lahore, Pakistan, \\ ${ }^{3}$ Health Services Academy, Islamabad, Pakistan, \\ ${ }^{4}$ Lahore College for Women university, Lahore, Pakistan, \\ ${ }^{5}$ Watim Dental College Rawalpindi, Pakistan, \\ ${ }^{6}$ National Institute of Health, Islamabad, Pakistan, \\ ${ }^{7}$ Contech School of Public Health, Lahore, Pakistan \\ Correspondence: smrmep@gmail.com,Ph: +92-42-35236662, 03004335628
}

\begin{abstract}
Background: Mental and psychological disorders are responsible for significant morbidity and disability worldwide. Results of World Mental Health Consortium demonstrate that common mental disorders are highly prevalent globally. Only a limited proportion of patients with psychiatric disorders attend the healthcare facilities, in severe condition. Treatment by unqualified medical practitioners and faith healers is a common practice, which significantly delay the proper treatment.

Methods: We conducted this survey at the psychiatry OPD at Jinnah Hospital Lahore from March 2015 to May 2015. 1000 study subjects of $14-70$ years of age from both genders were enrolled for this study randomly, who sought psychiatric opinion for first time.

Results: One hundred patients were examined, mean age of subjects was 31 years (SD + 15.02), with $53.0 \%$ females. More patients (60.0\%) were first time recognized by their family members, remaining sought treatment by themselves. As per history $42.4 \%$ patients had consulted to Qualified Medical General Practioners, $19.9 \%$ to Piers, $12.0 \%$ to Religious Clerics and $10.5 \%$ to Hakim, Fakir, Malang etc. and only $2.6 \%$ consulted to psychotherapist.

Conclusion: It is concluded that in our setting psychiatric illnesses are always recognized late and medical practitioners do not bother to obtain consultative opinion from psychotherapist.
\end{abstract}

Keywords: Mental illness, depression, treatment, hospital visits

\section{Introduction}

Mental disorders and their associated psychosocial disabilities are a source of considerable morbidity and impose a significant drain on national resources. The majority of the world's 450 million people suffering from psychiatric morbidity live in developing countries, and less than $10 \%$ have access to mental healthcare(1). It is important for mental healthcare professionals to be aware and sensitive to spiritual dimensions of mental health (2). A recent study assessing the implications of psychiatric phiralism for WHO search on mental health disorder examined patients in three forms of therapy for mental illness in South India, ayurvedric, allopathic and religious healing(3). The bulk of epidemiological research in Uganda has focused on primary care settings, where most psychiatric disorders are No.npsychotic $(4,5)$. The reported prevalence rates vary widely, from $10 \%$ to nearly half of all primary care attendees (the quoted figures range from $10-25 \%$ of patients attending with a psychiatric problem, with or without a co-existing physical problem). The most common diagnoses are depression and anxiety $(6,7,8)$. A community study from rural Uganda by Orley and Wing found the following prevalence: Depression 9.3\%, Anxiety $8.5 \%$, Bipolar disorder $4.9 \%$ and Schizophrenia $1.5 \%(9)$. In a study of households in the Kabarole district of Uganda, Kasoro and others found that $30.7 \%$ of adults had psychiatric disorders (10). On the basis of the UNHS 2005/2006 Qualitative Module Report, the Uganda Bureau of Statistics found, for example, that $58 \%$ of all the households with disabled members (an estimated $7 \%$ of all households in Uganda), had at least one member with a mental disorder (11). Furthermore, it is possible that many patients with psychosis do not 
spontaneously seek primary healthcare (12).A study in urban Tanzania the prevalence of common mental disorders was $48 \%$ (13). Patel and others found a prevalence of $40 \%$ in Harare (14). Study will reveal current trends and practices of health seeking behavior of patients suffering from psychiatric illness. The term mental illness is generally referred to mental health problems in adults (15). Significant disease load is attributed to mental illnesses globally and talking in terms of DALY (disability adjusted life years), a more reliable indicator, more than two fifth of total disabilities are due to mental illness (16). Out of the top ten leading causes of disabilities throughout the world, five are psychiatric illnesses (17).

In Pakistan number of studies have shown that many people attribute depression (which is a major psychiatric problem) to evil influences. Many parents believe in Jin, magic and evil eye for the mental illness of their child $(18,19)$. Studies have also shown that majority of the patients, who attend the spiritual healers are either uneducated or just had primary education $(20,21)$. This study was conducted to assess this aspect of our population so that steps could be taken for better provision of health facilities along with disease management and control (22). By permitting consideration of 'secular' spiritual activities and shortcircuiting destructive arguments about beliefs, a valuable perspective can be applied to the whole field of mental healthcare (23). It follows that psychiatric care should routinely include a careful and sympathetic assessment or 'spiritual screening' (24). Neuropsychiatric conditions together account for $10.96 \%$ of the global burden of disease as measured by disability-adjusted life years (DALYs) (25).

In most countries, families bear a significant proportion of these economic costs because of the absence of public funded comprehensive mental health service networks (26).

The belief that mental illness is incurable or self-inflicted can also be damaging, leading to patients No.t being referred for appropriate mental healthcare (27). It is pertinent to study the perceptions, myths, beliefs and health-seeking behavior for mental health of population (28). Reasons for choosing a particular service help in understanding how the population perceives mental illnesses and responds to them (29). This knowledge can be helpful in developing community awareness programs so as to remove myths and misconceptions about mental illnesses and sensitize the people with the availability of various sources of help available in the community (30).

\section{Methodology}

Cross sectional descriptive study in Psychiatric OPD Jinnah Hospital Lahore was conducted on 100 subjects and Purposive sampling was done. Patient with age 14 70 years of both gender and Patients seeking psychiatric opinion for first time was included in this study. A structured questionnaire was designed containing information regarding health seeking practices of psychiatric patients. Data was entered and analyzed in SPSS ver: 17.0. Mean and standard deviation was calculated for numerical variable like age. Frequency and percentage will be calculated for qualitative variables like diagnosis, gender distribution, faith healers visits and reason for faith healer visits.

\section{Results}

Mean age of subjects was 31 years SD +15.02 , median age 27 and mode 18. Minimum ages of subjects were 10 years and maximum ages of subjects were 80 years. (Table No-1) $67 \%$ urban and $33 \%$ rural $53.0 \%$ were females and $47.0 \%$ were males.

Table 1: Age of subjects

\begin{tabular}{|l|l|l|}
\hline Age of Respondents & Frequency & Percent \\
\hline $14-30$ years & 60 & 60.0 \\
\hline $31-60$ years & 32 & 32.0 \\
\hline 60 years and above & 8 & 8.0 \\
\hline Total & 100 & 100.0 \\
\hline
\end{tabular}

Education of subjects was found that $28.0 \%$ of subjects were illiterate, $21 \%$ had attended primary school and $14.0 \%$ had attended secondary school. Among the respondents $36.0 \%$ were illiterate, $21.0 \%$ had attended primary school and $10.0 \%$ attended secondary school. (Table No.: 3).

Table 3: Educational status of subjects and respondents

\begin{tabular}{|c|c|c|c|c|}
\hline \multirow[t]{2}{*}{ Education status } & \multicolumn{2}{|c|}{ Education status of subject } & \multicolumn{2}{|c|}{ Education status of respondent } \\
\hline & Frequency & Percent & Frequency & Percent \\
\hline Illiterate & 28 & 28.0 & 36 & 36.0 \\
\hline Primary & 12 & 12.0 & 7 & 7.0 \\
\hline Middle & 14 & 14.0 & 11 & 11.0 \\
\hline Matric & 21 & 21.0 & 21 & 21.0 \\
\hline F.A/F. Sc & 14 & 14.0 & 10 & 10.0 \\
\hline Bachelors \& above & 11 & 11.0 & 11 & 11.0 \\
\hline masters $\mathrm{n}$ above & 0 & 0.0 & 4 & 4.0 \\
\hline Total & 100 & 100.0 & 100 & 100.0 \\
\hline
\end{tabular}

Regarding the occupational status of the subjects, it was found that $26.0 \%$ were housewives, $22.0 \%$ were students and $20.0 \%$ were farmers. Among the respondent $35.0 \%$ were students, $19.0 \%$ were farmers/laborers and $18.0 \%$ were govt. employee/pvt. (Table No.: 4).

Table 4: Occupational statuses of subjects and respondents

\begin{tabular}{|l|l|l|l|l|}
\hline \multirow{2}{*}{ Occupation } & \multicolumn{2}{l|}{ Occupation of subject } & \multicolumn{2}{l|}{ Occupation of respondent } \\
\cline { 2 - 5 } & Frequency & Percent & Frequency & Percent \\
\hline Unemployed & 15 & 15.0 & 12 & 12.0 \\
\hline Farmer / Laborer & 20 & 20.0 & 19 & 19.0 \\
\hline Business & 8 & 8.0 & 12 & 12.0 \\
\hline Employee Govt. / Pvt. & 9 & 9.0 & 18 & 18.0 \\
\hline Student & 22 & 22.0 & 35 & 35.0 \\
\hline Housewife & 26 & 26.0 & 4 & 4.0 \\
\hline Total & 100 & 100.0 & 100 & 100.0 \\
\hline
\end{tabular}

$6.07 \%$ of subjects lived in urban areas and $33.0 \%$ lived in rural areas. (Graph No.: 2) Relationship of accompanying person was assessed and it was found that $42.0 \%$ were parents of subjects, $22.0 \%$ were 
relatives, $19.0 \%$ were siblings and $10.0 \%$ were spouses, who brought the subjects to OPD. (Table No.: 5).

\section{Table 5: Relation of respondents with subject}

\begin{tabular}{|l|l|l|}
\hline $\begin{array}{l}\text { Relation of respondents with } \\
\text { subject }\end{array}$ & Frequency & Percent \\
\hline Self & 4 & 4.0 \\
\hline Parents & 42 & 42.0 \\
\hline Spouse & 10 & 10.0 \\
\hline Siblings & 19 & 19.0 \\
\hline Relatives & 22 & 22.0 \\
\hline Friends & 3 & 3.0 \\
\hline Total & 100 & 100.0 \\
\hline
\end{tabular}

$40.0 \%$ of subject's symptoms where recognized in more than 2 years, $19.0 \%$ of subjects recognized symptoms within $1-2$ years. $66.0 \%$ of subjects took psychiatric consultation in $<6$ months, $13.0 \%$ of subjects took psychiatric consultation between 6 months to 2 years and $21.0 \%$ of subjects took psychiatric consultation for first time after two years (Table No. :6).

Table 6: Problem first recognized and Psychiatric consultations taken for first time:

\begin{tabular}{|l|l|l|l|l|}
\hline \multirow{2}{*}{ Duration } & \multicolumn{2}{|l|}{ Problem first recognized } & \multicolumn{2}{l|}{ Psychiatric consultation taken for first time } \\
\cline { 2 - 5 } & Frequency & Percent & Frequency & Percent \\
\hline$<6$ months & 30 & 30.0 & 66 & 66.0 \\
\hline $6-1$ year & 11 & 11.0 & 6 & 6.0 \\
\hline $1-2$ years & 19 & 19.0 & 7 & 7.0 \\
\hline$>2$ years & 40 & 40.0 & 21 & 21.0 \\
\hline Total & 100 & 100.0 & 100 & 100.0 \\
\hline
\end{tabular}

Regarding problem recognized first by whom and who convinced from treatment. $60.0 \%$ were the patients relatives who first recognized this problem, $36.0 \%$ of subjects themselves recognized their problem and sought for treatment. $4.0 \%$ subject's friend first recognized the symptoms. $68.0 \%$ subjects were convinced for treatment by their relatives, $21.0 \%$ themselves opted for treatment and $11.0 \%$ by their friends. (Table No.: 7).

Table 7: Problem recognized first by whom and who convinced for treatment

\begin{tabular}{|l|l|l|l|l|}
\hline $\begin{array}{l}\text { Relation of } \\
\text { respondents } \\
\text { with subject }\end{array}$ & Problem recognized first by whom & \multicolumn{2}{|l|}{ Who convinced for treatment } \\
\cline { 2 - 5 } & Frequency & Percent & Frequency & Percent \\
\hline Self & 36 & 36.0 & 21 & 21.0 \\
\hline Relative & 60 & 60.0 & 68 & 68.0 \\
\hline Friend & 4 & 4.0 & 11 & 11.0 \\
\hline Total & 100 & 100.0 & 100 & 100.0 \\
\hline
\end{tabular}

Consultation taken by respondents for subjects was also asked and it was found that $42.4 \%$ consultations were from GP, $19.9 \%$ from Pier, $12.0 \%$ from Religious Clerics and $10.5 \%$ from Hakim, Fakir and Malang accounted for $5.7 \%$ and only $2.6 \%$ consultants were taken from psychotherapist. When asked about the mode of treatment from the respondents, it was found that $44.4 \%$ of the subjects used drugs, $29.3 \%$ dum, $23.6 \%$ taweez and $3.1 \%$ used exorcism/violence as a treatment modality. (Table No.: 8 \& 9).
Table 8: Frequencies of Consultation taken from different modalities

\begin{tabular}{|l|l|l|l|}
\hline \multirow{2}{*}{ Consultation taken from } & Responses & Percent of Cases \\
\cline { 2 - 4 } & $\mathrm{N}$ & Percent & \\
\hline GP & 81 & $42.4 \%$ & $81.0 \%$ \\
\hline Homeopath & 13 & $6.8 \%$ & $13.0 \%$ \\
\hline Hakim & 20 & $10.5 \%$ & $20.0 \%$ \\
\hline Pier & 38 & $19.9 \%$ & $38.0 \%$ \\
\hline Religious Clerics & 23 & $12.0 \%$ & $23.0 \%$ \\
\hline Fakir & 9 & $4.7 \%$ & $9.0 \%$ \\
\hline Psychotherapist & 5 & $2.6 \%$ & $5.0 \%$ \\
\hline Malang & 2 & $1.0 \%$ & $2.0 \%$ \\
\hline Total & 191 & $100.0 \%$ & $191.0 \%$ \\
\hline
\end{tabular}

Table 9: Mode of treatment

\begin{tabular}{|l|l|l|l|}
\hline \multirow{2}{*}{ Mode of treatment } & \multicolumn{2}{|l|}{ Responses } & Percent of Cases \\
\cline { 2 - 3 } & $\mathrm{N}$ & Percent & \\
\hline Drugs & 84 & $44.0 \%$ & $84.8 \%$ \\
\hline Tweeze & 45 & $23.6 \%$ & $45.5 \%$ \\
\hline Dum & 56 & $29.3 \%$ & $56.6 \%$ \\
\hline Exorcism/Violence & 6 & $3.1 \%$ & $6.1 \%$ \\
\hline Total & 191 & $100.0 \%$ & $192.9 \%$ \\
\hline
\end{tabular}

The frequency of consultation was that $48.0 \%$ received consultation $1-3$ times, $37.0 \%$ more than 6 times and 15.0\% 4-6 times. (Table No.: 10).

Table 10: How many times consultation received

\begin{tabular}{|l|l|l|}
\hline How many times consultation received & Frequency & Percent \\
\hline $1-3$ times & 48 & 48.0 \\
\hline $4-6$ times & 15 & 15.0 \\
\hline$>6$ & 37 & 37.0 \\
\hline Total & 100 & 100.0 \\
\hline
\end{tabular}

When asked about their opinion for satisfaction about different treatment modalities, it was found that $54.9 \%$ were satisfied from drugs, $25.4 \%$ from dum, $18.0 \%$ from taweez and $1.6 \%$ from exorcism/Violence. (Table No.: 11).

Table 11: Satisfaction about treatment Frequencies

\begin{tabular}{|l|l|l|l|}
\hline Treatment & \multicolumn{2}{l|}{ Satisfied Responses } & Percent of Cases \\
\hline & $\mathrm{N}$ & Percent & \\
\hline Drug & 67 & $54.9 \%$ & $83.8 \%$ \\
\hline Taweez & 22 & $18.0 \%$ & $27.5 \%$ \\
\hline Dum & 31 & $25.4 \%$ & $38.8 \%$ \\
\hline Exorcism / Violence & 2 & $1.6 \%$ & $2.5 \%$ \\
\hline Total & 122 & $100.0 \%$ & $152.5 \%$ \\
\hline a. Dichotomy group tabulated at value 1. & & \\
\hline
\end{tabular}

\section{Discussion}

The World Health Organization noted that one in every four people is affected by a mental disorder at some stage of life (31). Six neuropsychiatry conditions, have figured in the top causes of disability in the world (32).in India, $2-5 \%$ of the population is suffering from serious mental illnesses, while another $10 \%$ of the population is suffering with minor mental illnesses(33-3). In India, there are a very small number of qualified psychiatrists (34). The non-availability of mental health services, penury, stigma, and superstitions associated with mental disorders, coupled with the unwillingness or 
inability of families to care of their mentally ill relatives, appear to be the main contributory factors(35).

The criterion used to assess the mental illnesses was William C Menninger criteria which showed that education had a significant association with health seeking behavior $(p<0.05)$ and No. significant difference was found in health seeking behavior of males and females $(p>0.05)(36)$. In our study $53.0 \%$ were females and $47.0 \%$ were males and $28.0 \%$ of subjects were illiterate, $21 \%$ had attended primary school and $14.0 \%$ had attended secondary school. Among the respondents $36.0 \%$ were illiterate, $21.0 \%$ had attended primary school and $10.0 \%$ attended secondary school.

They likely influence the family's help-seeking decisions and affect both adherence with biomedical interventions and social integration of the patients (37).

Mean age of subjects were 31 years SD +15.02 , median age 27 and mode 18. Minimum ages of subjects were 10 years and maximum ages of subjects were 80 years. (Table No.: $1 \&$ 2) $53.0 \%$ were females and $47.0 \%$ were males. Among the respondent $35.0 \%$ were students, $19.0 \%$ were farmers/laborers and $18.0 \%$ were govt. employee / pvt. (Table No.: 4). $6.07 \%$ of subjects lived in urban areas and $33.0 \%$ lived in rural areas.

In our study consultations taken by respondents for subjects was also asked and it was found that $42.4 \%$ consultations were from GP, $19.9 \%$ from Pir, $12.0 \%$ from Religious Clerk and $10.5 \%$ from Hakim, Fakir and Malang accounted for $5.7 \%$ and only $2.6 \%$ consultant were taken from psychotherapists. When asked about the mode of treatment from the respondents, it was found that $44.4 \%$ of the subjects used drugs, $29.3 \%$ dum, $23.6 \%$ taweez and $3.1 \%$ used exorcism/violence as a treatment modality(38).

\section{Conclusion}

The conclusion of our study is:

* There is a delay in recognition of psychiatric illnesses in our setting.

* Parents seem to be more concerned about taking treatment from psychiatric facility.

* $\quad$ Faith healers consultations are significantly sought in our community.

* Satisfaction level regarding allopathic treatment

\section{Acknowledgements} is more than spiritual healing practices.

We are deeply grateful to the Head of Department and allied staff of psychiatric department of Jinnah Hospital Lahore for their facilitation for data collection.

\section{References}

1. Abbo C. Profiles and outcome of traditional healing practices for severe mental illnesses in two districts of Eastern Uganda. Glob Health Action. 2011; 4.

2. WHO. Geneva: World Health Organization; 2005. Mental health atlas.

3. Muhwezi W, Agren H, Musisi S. Detection of Major Depression in Ugandan Primary Health Care using simple questions from a Subjective Well Being
(SWB) subscale. Soc Psychiatry Psychiatr Epidemiol. 2007;42:61-69.

4. Patel V, Todd C, Parry C, Njenga FG. Epidemiology of mental disorders in sub-Saharan Africa. In: Njenga FG, Acuda W, Patel V, Maj M, editors. Essentials of Clinical Psychiatry for Sub-Saharan Africa. Milano: Masson; 2005. pp. 56-61.

5. Gureje O, Obikoya B, Ikuesan BA. Prevalence of specific psychiatric disorders in an urban primary care setting. East African Medical Journal. 1992;69:17-21.

6. Gureje O, Lasebikan VO, Kola L, Makanjoula VA. Lifetime and 12-month prevalence of mental disorders in the Nigerian Survey of Mental Health and Well-Being. Br J Psychiatry. 2006;188(5):465471.

7. Orley J, Wing J. Psychiatric Disorders in Two African Villages. Arch Gen Psychiatry. 1979;36:513-557.

8. Kasoro S, Sebudde S, Kabagambe-Rugamba S, Ovuga EB, Boardman A. Mental illness in one district in Uganda. International Journal of Social Psychiatry. 2002;48:29-37.

9. Uganda Bureau Statistics, UNHS. Kampala: 2005/2006. Qualitative Module Report.

10. Abbo C, Okello ES, Ekblad S, Waako P, Musisi S. Lay concepts of psychosis in Busoga, Eastern Uganda: a pilot study. J World Cultural Psychiatry Research Review. 2008; 3(3):132-145.

11. Ngoma MC, Prince M, Mann A. Common mental disorders among those attending primary health clinics and traditional healers in urban Tanzania. $\mathrm{Br}$ J Psychiatry. 2003; 183(4):349-355.

12. Patel V. Use of traditional and orthodox health services in urban Zimbabwe. Internal Journal of Epidemiology. 1997; 32:97-103.

13. The World Health Report 2001, WHO, Switzerland. www.mentalhealth.samhsa.gov/publications. Cited on Oct-2005.

14. Murray L, Lopez A. The global burden of diseases, joint publication of World Bank and Harvard University, Harvard Press, U.S.A. 1996:3-18.

15. Gadit AA, Khalid N. State of mental health in Pakistan-Service Education and Research. Hamdard Foundation, Karachi. 2003:10-53.

16. Absar A, Amin GA. Depression in cultural context. Medical Spectrum 1998;19:10-12.

17. Gadit AA. Ethno psychiatry in peds. Medical spectrum 1997;18:28.

18. Gadit A. Scope of Ethno psychiatry in Pakistan. (Editorial) J Pak Med Assoc 1996; 46:119.

19. Razali M. Psychiatrists and Folk healers in Malaysia. WHO Forum, 1995;16:56-9.

20. Gadit AA. State of mental health in Pakistan. (Editorial), J Pak Med Assoc 2001;51:238

21. Gadit AA. Ethno psychiatry. J Pak Med Assoc. 2003; 53:483-90

22.Swinton J. Spirituality and Mental Health Care: Rediscovering a Forgotten Dimension. London: 
Jessica Kingsley, 2001. A masterly and insightful overview.

23. Koenig H. Spirituality in Patient Care: Why, How, When and What. Philadelphia, London: Templeton Foundation Press, 2002. A slim, informative paperback.

24. Levin J. God, Faith and Health: Exploring the Spirituality-Healing Connection. New York, Chichester: John Wiley and Sons, 2001. A thoughtprovoking and readable book by a medical epidemiologist with engaging ideas and patient narratives to match them.

25. Dasgupta R, Dasgupta C. CATIE and CUtLASS (UK): Is it time psychiatrists start changing their practice? The debate goes on! Indian J Psychiatry. 2009; 51:161-2.

26. Bagadia VN, Shah LP, Pradhan PV, Gada MT. Treatment of mental disorders in India. Progress in Neuropsychopharmacology. 1979;3:109-18.

27. Shamasundar C. Relevance of ancient Indian wisdom to modern mental health - A few examples. Indian J Psychiatry. 2008; 50:138-43.

28. Bhana K. Indian indigenous healers. South African Med J. 1986;70:221-3.

29. Loganathan S, Murthy SR. Experiences of stigma and discrimination endured by people suffering from schizophrenia. Indian J Psychiatry. 2008; 50:39-46.

30. Banerjee T, Banerjee G. Determinants of helpseeking behaviour in cases of epilepsy attending a teaching hospital in India: An indigenous explanatory model. Intl J Social Psychiatry. 1995;41:217-30.

31. Mental health: New understanding, New hope: World Health Report 2001.Geneva: World Health Organization; 2001. Geneva: World Health Organization; 2001. World Health Organization; pp. 09-24.

32. Murray CJL, Lopez AD. Mortality by cause for eight regions of the world: Global Burden of Disease Study. Lancet. 1997;349:1269-76.

33. National Mental Health Program. New Delhi: NIHFW; 2005. National Institute of Health and Family Welfare.

34. Mental Health: An Indian Perspective, 1946-2003. New Delhi: Directorate General of Health Services; 2004. Government of India; pp. 4-17.

35. Rogler LH, Cortes DE. Help-seeking pathways: A unifying concept in mental health care. Am J Psychiatr. 1993;150:554-61.

36. Ali F, Sami F, Rehman H, Siddique I, Haider K. Relation of gender education and health seeking behaviour of the general population regarding psychiatric illness. J Pak Med Assoc. 2006 Sep; 56(9):421-2.

37. Bouhlel S, Ben Haouala S, Klibi A, Ghaouar M, Chennoufi L, Melki W, El-Hechmi Z. [Assessing beliefs and attitudes of relatives of patients with schizophrenia: A study in a Tunisian sample.]
Encephale. 2012 Jul 12. pii: S0013-7006(12)001066. doi: 10.1016/j.encep.2012.06.012.

38. Madianos MG, Madianou D, Stefanis CN. Helpseeking behaviour for psychiatric disorder from physicians or psychiatrists in Greece. Soc Psychiatry Psychiatr Epidemiol. 1993 Nov; 28(6):285-91. 